\title{
Code of Ethics as a Tool of Management in Academic Environment: Case of Armenia ${ }^{1}$
}

\section{Tereza KHECHOYAN ${ }^{1}$, Gayane HOVHANNISYAN ${ }^{2 *}$}

1 Associate Professor, Head of Ethics Commission, Public Administration Academy of the Republic of Armenia, khechoyantereza@yahoo.com;

2 Head of the Quality Assurance Center, Researcher of Research Center for Management of Science, Public Administration Academy of the Republic of Armenia;

* Correspondence: khechoyantereza@yahoo.com

Citation: Khekhoyan, T. \& Hovhannisyan, G. (2021). Code of Ethics as a Tool of Management in Academic Environment: Case of Armenia. Revista Etică și deontologie. 1 (1), $10-17$

https://doi.org/10.52744/RED.2021.01.02

Publisher's Note: RED stays neutral with regard to jurisdictional claims in published maps and institutional affiliations.

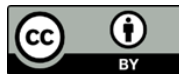

Copyright: (C) 2021 by the authors. Submitted for possible open access publication under the terms and conditions of the Creative Commons Attribution (CC BY) license

(https://creativecommons.org/licens es/by/4.0/)

\begin{abstract}
The paper deals with the role and importance of the code of academic ethics as a tool of education and management in modern educational environment, it also reviews the challenges associated with development and introduction of the code in the academic environment.

The outcomes of the study of the procedure of developing and introducing the code of ethics in HEI's management are presented as the main document underlying the formation of corporate culture in any educational institution. The study was based on the results of surveys on Code of Ethics in Academic Environment conducted among the staff and students of Public Administration Academy of RA, and The Effects of the Current Emergency Situation on the Daily Tasks of the Staff of Armenian Scientific and Educational Organizations.

The analysis of the attempts to create a Code of Ethics allows one to conclude that although such codes are needed as regulators of relationships among all participants of educational process, there are no unified approaches or suggestions for their formation.

The analysis has revealed that the legislation on education in Armenia is lacking provisions on code of ethics or ethic rules: the imperfection of mechanisms of applying these provisions is obvious. Legal provisions related to regulation of ethical dilemmas as well as building efficient framework for their supervision need to be developed.

It is worth noting that the Draft Law on Higher Education and Science has added a number of provisions to be addressed in this article.
\end{abstract}

Keywords: Code of Ethics, Code of Conduct, Academic Integrity, Online Teaching and Research

\footnotetext{
${ }^{1}$ Articol prezentat în cadrul Conferinței Internaționale Valorile Etice în Societatea Actuală - VESA 2021 (3-5 iunie).
} 


\section{Introduction}

Ethical behavior, the established code of ethics and its efficient practical application are of highest importance in education system, particularly, in higher education.

The analysis of attempts to create codes of ethics allows one to conclude that although such codes are much in demand as regulators of relationships among all groups participating in the education, there are no unified approaches or suggestions for their formation.

The code of conduct sets particular standards of behavior to guide the representatives of academic system as to how to behave in certain situations. Besides, these codes outline the principles of transparency and public accountability in research and education activities.

It is noteworthy that based on the outcomes of the review of local and foreign higher education institutions, we reached a conclusion that the principles of academic ethics have no essential distinctions since they are rooted in common human values such as integrity, transparency, dependability, mutual respect, etc. (Stanford University Code of Conduct. Howard University Code of Ethics and Conduct. Кодекс этики научно-педагогического работника НИУ ВШЭ, 2020. Кодекс этики обучающихся НИУ ВШЭ, 2020).

The Codes of Ethics help meet the increasingly growing expectations of the public about the education system as well as define the higher educational institutions' responsibility degree. The Codes of Ethics can contribute to enhancement of mutual trust between the public and higher educational institutions.

Higher educational institutions should design and implement fair and consistent policy, relevant procedures and response mechanisms aimed at preparation of programs for enhancement of academic ethics and awareness.

Enforcement of Code of Ethics may be fostered also by the pressure exerted by the public to ensure transparency of the system.

Rodney Erakovich and Sherman Wyman having examined the role of organizational culture believe that within the organization the leader's role is of utmost importance. S/he can by her/his own behavior introduce a certain frame of values to set the permissible and encouraging behavior types (Erakovich R., Wyman S., 2009).

They, in essence, criticize the normative approach to introduction of ethics with accentuation of ethical guidelines; instead they recommend establishing an ethical culture to comply with the organization's mission and goals.

The academic public has a set of non-formal rules and traditions which are nowhere described or discussed although assumed to the quite understandable.

Rules-based code of conduct concentrates on the things we are unable to perform while values-based code of conduct focuses on the things desired.

The analysis of the attempt to create a code of ethics allows us to state that, on one hand, they are much demanded as regulators of relationships among all groups 
of participants of the education process, while on the other hand, there are no unified approaches and recommendations for their formation.

\section{Materials and Methods}

We have conducted surveys in the Public Administration Academy of the Republic of Armenia and in other Armenian higher educational institutions. The analysis revealed a number of phenomena occurring in the academic environment.

Code of Conduct of the Public Administration Academy of the Republic of Armenia (PAARA) has been approved by the Scientific Board in 2015. In 2021 PAARA Quality Assurance Center conducted survey among the staff and students of the Academy on Code of Ethics in Academic Environment which was a source of information on current state of human resources management and will be instrumental in improving the Code of Conduct and Toolkit.

Besides, survey on Effects of the Current Emergency Situation on the Daily Tasks of the Staff of Armenian Scientific and Educational Organizations was conducted in 2021 by the Public Administration Academy of RA Quality Assurance Center.

The Strengthening Integrity and Fighting Corruption in Education: Armenia Report (Open Society Foundations - Armenia and Center for Applied Policy Team) was used in this article as a source of academic integrity investigation.

The survey on Code of Ethics in Academic Environment involving 54 students and 39 academic staff of PAARA as respondents, reveals that

$\checkmark$ 63.4\% of respondents were aware about Academy's Code of Conduct.

$\checkmark 60.2 \%$ of respondents were unaware about Academy's Ethics Commission.

$\checkmark 20.4 \%$ of respondents encountered a problem but failed to apply to the Ethics Commission.

The majority of them could not overcome the fear of being criticized or were not sure they would succeed, so they refrained from turning to the Ethics Commission for solving their problems.

A number of ethical problems linked to the COVID-19 pandemic have arisen in academic environment, while the targeted survey reveals challenges of online education in Armenia.

The figures on challenges and advantages of online teaching represented below, illustrate our conclusions concerning the objectivity of students' knowledge assessment in the case of online teaching and learning (The Effects of the Current Emergency Situation on the Daily Tasks of the Staff of Armenian Scientific and Educational Organizations Survey, 2021).

Answers to the following questions on challenges of online education are shown by the figure 1 :

$\checkmark \quad$ It is not possible to fully assess a student's knowledge (14.7\%)

$\checkmark \quad$ It is difficult to conduct practical exercises (16.6\%)

$\checkmark \quad$ It is difficult to understand whether the student understood the material or not $(16.6 \%)$ 
$\checkmark \quad$ It is difficult to prevent various manipulations while the student is responding $(17.5 \%)$

$\checkmark \quad$ It is necessary to apply a new methodology, for which the previous teaching methods should be reviewed, which requires additional efforts from the lecturer $(9.7 \%)$

$\checkmark \quad$ The lecturer and the student must adapt to the new technical means and master them (5.1\%)

$\checkmark \quad$ Online teaching has no difficulties, you just have to adapt (3.7\%)

$\checkmark$ Bad communication often causes problems (15.2\%)

$\checkmark \quad$ I find it difficult to answer (0.9\%).

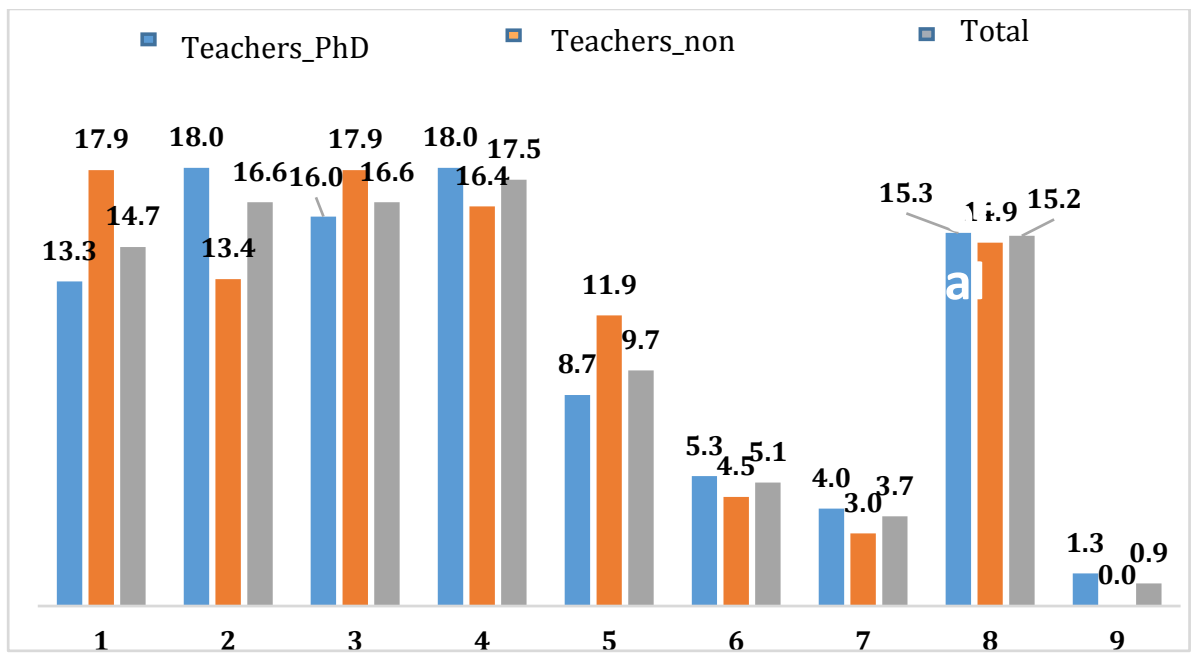

Figure 1. Analysis of Challenges of Online Teaching, \%

Figure 2 illustrates answers to the following questions on advantages of online education:

1. Allows objective assessment of students' knowledge (1.1\%)

2. Allows you to work on a flexible schedule (17.1\%)

3. Provides opportunities to provide more materials to students (7.4\%)

4. Enables more active monitoring of student participation (1.7\%)

5. Gives the opportunity to be in constant contact with students (4.6\%)

6. Gives students the opportunity to express their thoughts freely, to raise various issues related to the topic (3.4\%)

7. Gives an opportunity not to lag behind the educational process in the current situation (22.3\%)

8. Enables working students to be more actively involved in the learning process $(11.4 \%)$

9. The personal expenses of the lecturer and student (transportation and other expenses) are reduced (21.7\%)

10. Online teaching has no advantages over existing teaching (8.6\%)

11. I find it difficult to answer $(0.6 \%)$ 

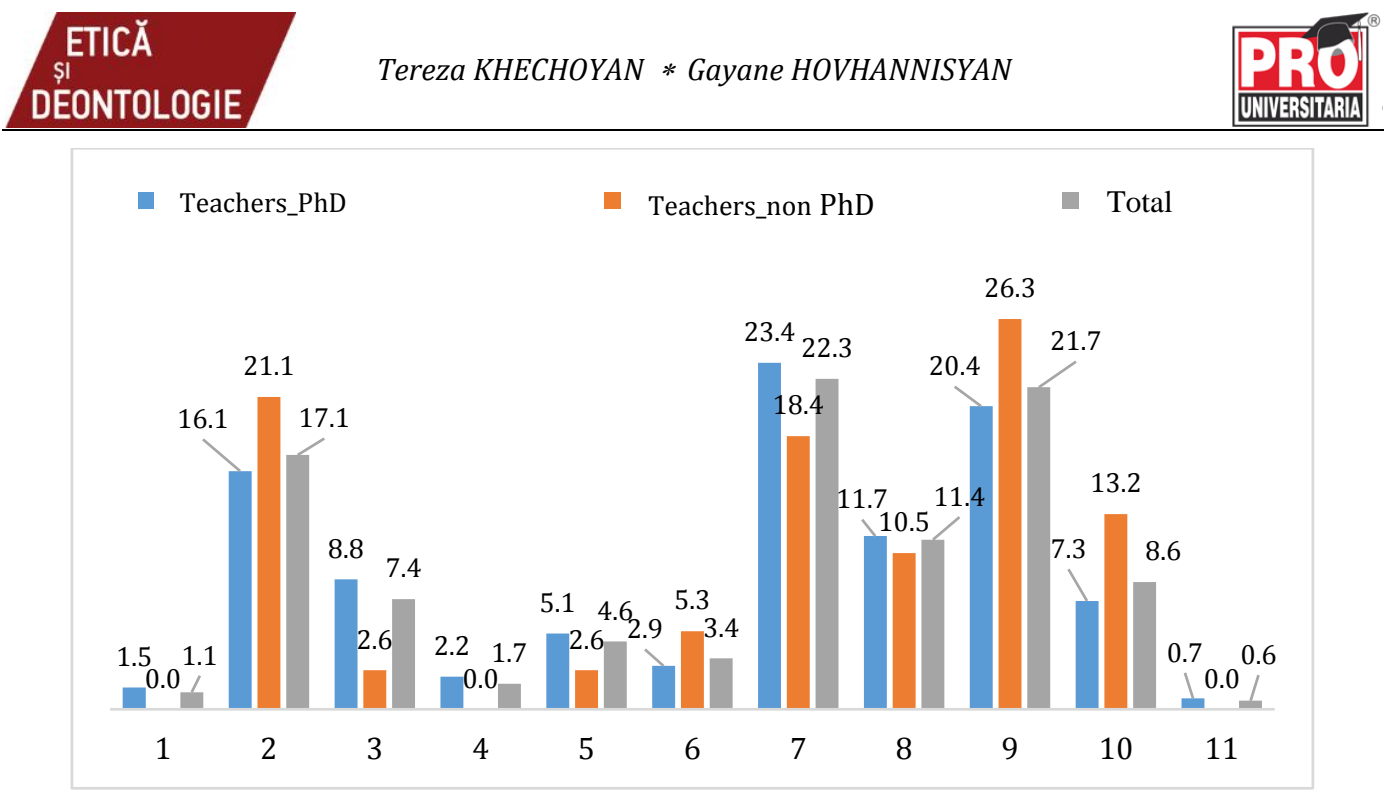

Figure 2. Advantages of Online Teaching, \%

The analysis of the data of the above figures allows to reach the following conclusions:

1. Only $1.1 \%$ of respondents/academic staff from Armenian Universities were sure that online education allows objective assessment of students' knowledge.

2. Only $1.7 \%$ of them think that online education enables more active monitoring of student participation.

3. $17.5 \%$ of them think it difficult to prevent various manipulations by a student when answering a question in a quiz.

4. $15.2 \%$ of them pointed out several problems often caused by poor communication.

5. $14.7 \%$ of them deemed it impossible to fully assess student's knowledge.

6. $16.6 \%$ of them pointed out the difficulties associated with practical exercises and knowledge objective assessment.

These data indicate that there is a need to include the cases of emergencies (e.g. pandemics) in the Code of Ethics.

According to the Strengthening Integrity and Fighting Corruption in Education: Armenia Report (Strengthening Integrity and Fighting Corruption in Education: Armenia Report, 2015),

* Academic dishonesty (plagiarism, for example) is quite common.

Two-thirds of the 125 students participating in a survey conducted among five Armenian universities, reported on regularly using and copying up to a third of their written works from Internet sources or elsewhere without attributing authorship.

* Factors that create opportunities for the integrity violation:

$\checkmark \quad$ Ignorance and impunity

$\checkmark \quad$ Deficient detection mechanisms

* Undue recognition of academic achievement: 
$\checkmark \quad 62 \%$ of those students, who stated they were aware of corruption in their universities, admitted bribing their teachers to pass an exam.

$\checkmark$ The majority of bribing students (56\%) have done this more than once.

$\checkmark \quad$ It is an indication that purchasing of academic recognition might have become part of the institutional culture at the universities surveyed.

* Factors that create opportunities for the integrity violation:

$\checkmark$ Impunity and low accountability with regards to rules of academic recognition

$\checkmark \quad$ Limited independence of quality assurance bodies.

* Factors that create incentives for the integrity violation:

$\checkmark$ Financial dependency on fee-paying students

- Due to the shortage of public resources, tertiary institutions naturally tend to prioritize fee-based income and fee-paying students over those who are studying "for free”. The conditions under which they operate push them strongly into an institutional attitude that can be best described as "the more students - the more money - the better".

- The analysis has revealed that the disproportionate reliance by public universities on tuition fees creates a strong incentive to treat the group of fee-paying students more favorably, for example by lowering achievement requirements.

Financial dependency on fee-paying students:

- In order to limit the negative influence of this factor, the side effects of dependency of public universities on fees and fee-paying students should be eliminated, mainly by reducing this dependency to manageable levels.

- The first and most difficult recommendation to follow is to increase public spending on higher education.

Deficient hiring and firing procedures and practices:

$\checkmark \quad$ The legislative framework grants public universities full autonomy to determine their human resource policies.

$\checkmark \quad$ These include the definition of staffing needs, the development of procedures for hiring and firing of staff at all levels of the institutional hierarchy, and the final decision of who gets or loses a job.

$\checkmark \quad$ There is no external accountability for any of these decisions, but there are robust channels for external influence, mostly opened through the governance structures of the universities with the help of persisting regulatory ambiguities.

$\checkmark \quad$ The government appoints a majority representation in the Councils (Governing Boards) of the public higher education institutions and places a politically affiliated figure to be the Chair.

$\checkmark$ The Rector's Councils - entities that, among other things, have the final say on staff policies and staff-related decisions including hiring and 


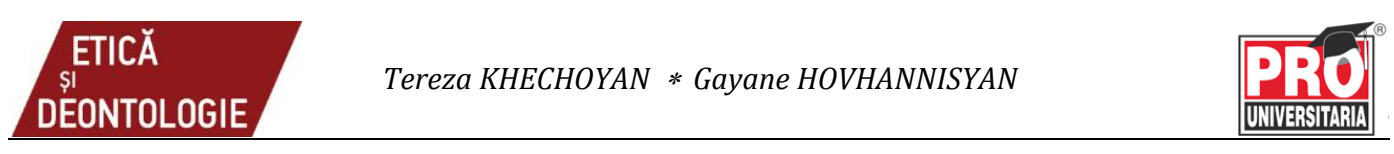

firing - follow orders that are defined by the politically captured Governing Boards.

\section{Results}

- A punishment provision for cheating and plagiarism is needed (in case of more than $20 \%$ of plagiarism students are subject to removal)

- Rules and Regulations are not sufficient to overcome ethics-related challenges

- Establishment of professional ethics culture will create favorable conditions for relationships among various students and those among students and teachers.

- Transparency and accessability of the Code are highly needed.

- The management of the Academy should take preventive measures to eliminate any kind of misconduct.

- In order to make the Code a part of organizational structure, it is necessary to find ways to enhance the staff's and students' awareness of it.

- The Code is more effective, if it adequately reflects the culture of the organization.

- There is a need to include the cases of emergencies (e.g. pandemics) in the Code of Ethics.

The analysis has shown that the Armenian laws on education are lacking provisions of code of ethics or ethic rules: here we encounter deficient mechanisms of applying these provisions. It is noteworthy that Armenia deems it very important in the context of implementing reforms in higher education and science; it is noteworthy that the draft Armenian Law on Higher Education and Science already has a number of relevant provisions incorporated in it. Thus,

Under clause 1, part 1, article 3 of the draft law, academic ethics means carrying out research and educational activities in compliance with professional ethics: professional behavior principles and moral conduct rules.

The draft law envisages that the higher educational institutions besides the strategic and annual plans should develop and publicize academic ethics code (part 8 , article 6 of the draft law).

Pursuant to part 5, article 7 of the draft law, research entity at least once every 5 years should develop and publicize its five-year strategic plan and code of academic ethics.

The approval of model code of academic ethics is within the competencies of the relevant body in charge of higher education and science (clause 8, part 1, article 21 of the draft law), while the review and approval of the code of academic ethics should be performed by the higher educational institutions' academic board (clause 11, part 5, article 31 of the draft law).

The violation of the requirement stated in the Law should also entail legal liability.

Under clause 3, part 3, article 36 of the draft law, a student is obliged to follow the requirements of the code of academic ethics. Such an obligation is also assigned 
to employee of a higher educational institution and research entity (clause 3, part 20, article 37 of the draft law).

Codes of ethics help meet the increasingly growing expectations of public and education system as well as establish responsibility to higher educational institutions, these measures may foster the mutual trust between public and higher educational institutions.

With consideration of the fact that possibilities of model code of ethics are limited to the tasks of regulating the relationships among education process participants, it is appropriate to implement further surveys and projects towards social responsibility and social security of all groups of individuals participating in the education process, which we consider an important component of the process.

The practical importance of a model code is associated with the possibility of formation of a corporate culture by higher educational institutions based on a unified approach, creation of manageable climate among the staff members, on-going perfection of the situation, establishment and maintenance of higher educational institutions appealing image when dealing with external environment based on the attractive behavior of each of the staff and fair partnership principles, mobilization of all resources of staff members and students to achieve common goals.

Student organizations should regularly conduct surveys in various higher educational institutions on cases of violation of ethical rules, while the outcomes of the surveys should be made publicly available.

\section{References}

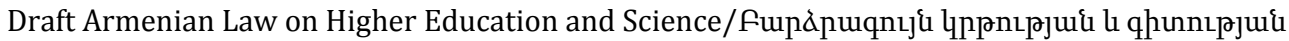
Uuuhi $2 z$ optiqph \{uupuuqho. Retrieved at: http://parliament.am/drafts.php?sel $=$ showdraft $\&$ DraftID $=12066 \&$ Reading $=0$

Erakovich R., Wyman S., Social Role of Public Organization Ethics Building in Local Governance in the Balkans, 2009, pp. 3-4.

Howard University Code of Ethics and Conduct. Retrieved at: http://www.howard.edu/ policy/codeofethics.pdf

Report of Survey Results on "Code of Ethics in Academic Environment”, 2021. Retrieved at: https://paara.am/wp-content/uploads/2012/10/цuppuqhל.pdf

Stanford University Code of Conduct. Retrieved at: https://adminguide.stanford.edu/chapter1/subchapter-1/policy-1-1-1

Strengthening Integrity and Fighting Corruption in Education: Armenia Report (Open Society Foundations - Armenia and Center for Applied Policy Team: Meri Avetisyan, Ivana Ceneric, Tetiana Khavanska, Mihaylo Milovanovitch), 2015; Publisher: Open Society Foundations-Armenia \& Center for Applied Policy. Retrieved at: http://www.osf.am/wpcontent/uploads/2016/01/Integrity-report_final_en_12.11.2015.pdf

The Effects of the Current Emergency Situation on the Daily Tasks of the Staff of Armenian Scientific and Educational Organizations Survey, 2021. Retrieved at: https://paara.am/ wp-content/uploads/2017/07/htinqnun.pdf

Кодекс этики научно-педагогического работника НИУ ВШЭ, 2020. Retrieved at: https://www.hse.ru/our/news/357670900.html

Кодекс этики обучающихся НИУ ВШЭ, 2020. Retrieved at: https://www.hse.ru/ our/ news/424081845.html 